\title{
National audit of higher training posts in child and adolescent psychiatry in Ireland
}

\author{
Dermot P. Cohen ${ }^{1}$
}

The Psychiatrist (2010), 34, 351-353, doi: 10.1192/pb.bp.109.028191

${ }^{1}$ St John of God Hospital, Stillorgan, Ireland

Correspondence to Dermot P. Cohen (dermotcohen@gmail.com)

\begin{abstract}
Aims and method The audit aimed to assess current senior registrar posts in child and adolescent psychiatry in Ireland in terms of working environment, conditions and training issues. The posts were compared with standards set down by the Child and Adolescent Psychiatry Specialist Advisory Committee of the Royal College of Psychiatrists and the National Higher Training Subcommittee of the Irish Psychiatric Training Committee.
\end{abstract}

Results The audit cycle was completed twice and a 100\% response rate was achieved on both occasions.

Clinical implications Higher training posts in child and adolescent psychiatry in Ireland compare favourably to standards for training and education, but poorly for working environment, case-load and educational supervision.

Declaration of interest None.
Over the past years, there has been a large increase in the number of senior registrars in child and adolescent psychiatry in Ireland, from 7 posts in 2001 to 27 in 2008. With such a rise, there has been increased pressure on training schemes to address training needs and working conditions of senior registrars.

The audit was based on guidelines on training and post requirements issued by the Child and Adolescent Psychiatry Specialist Advisory Committee of the Royal College of Psychiatrists (CAPSAC) ${ }^{1}$ and those included in the training handbook issued by the National Higher Training Subcommittee (NHTS) of the Irish Psychiatric Training Committee. ${ }^{2}$ From 1 January 2009, the new College of Psychiatry of Ireland became responsible for training in Ireland, with the assessment of individual training schemes as one of its crucial functions. The College is currently in the process of structuring accreditation procedures for higher training schemes.

Previous studies have examined the supervision process, ${ }^{3,4}$ access to information technology ${ }^{5}$ (IT) and case-load $^{6}$ on several training schemes in psychiatry in the UK. This was the first audit completed that provides a comprehensive review of various aspects of senior registrar posts on the national higher training scheme in child and adolescent psychiatry in Ireland.

\section{Method}

The audit cycle was completed twice. A questionnaire, based entirely on CAPSAC and NHTS handbook guidelines, was devised and circulated to all senior registrars (including D.P.C.) on the national rotation. Questions were divided into sections examining:
- working environment (office space and IT access)

- working conditions (case-load, administration duties and on-call commitments)

- training (supervision, education and research time).

Notes were also made of the type of service in which the senior registrar was working, for example day hospital or community service, as case-loads in these settings varied considerably. A report for the national specialty director and regional training programme directors was prepared and submitted after each audit cycle. All results were pooled to reflect national trends. Only case-load was examined differently, with point case-loads for community posts calculated separately from those posts in in-patient, day hospital or liaison settings.

\section{Results}

All senior registrars in full-time posts at the time of the audit were approached ( $n=25$ in 2007 and $n=27$ in 2008) and a $100 \%$ response rate was achieved in both cycles. (In 2007, one senior registrar was split between two clinical settings and reported on working environment for both, hence $n=26$ in 2007 for working environment.)

\section{Working environment}

All senior registrars reported some access to a PC, although $23 \%$ reported sharing their computer with at least two other people in 2007 (Table 1). Most worryingly, only a fifth reported having an alarm fitted in the office or a personal alarm (20\% in 2007 and $22 \%$ in 2008). 
Table 1 Working environment

\begin{tabular}{lcc} 
& \multicolumn{2}{c}{ Senior registrars who answered yes, \% } \\
\cline { 2 - 3 } Guideline & $\begin{array}{c}\text { First audit cycle } \\
2007\end{array}$ & $\begin{array}{c}\text { Second audit cycle } \\
2008\end{array}$ \\
\hline Own office & 50 & 56 \\
\hline Own PC & 44 & 67 \\
\hline Internet access & 88 & 93 \\
\hline Printer access & 85 & 82
\end{tabular}

Table 2 Case-load in community placements

\begin{tabular}{lcc} 
Case-load, $n$ & $\begin{array}{c}\text { First audit cycle } \\
2007, \%\end{array}$ & $\begin{array}{c}\text { Second audit cycle } \\
2008, \%\end{array}$ \\
\hline $20-29$ & 12 & 20 \\
\hline $30-39$ & 32 & 15 \\
\hline $40-49$ & 28 & 30 \\
\hline 50 & 28 & 35
\end{tabular}

\section{Working conditions}

Table 2 outlines case-loads of those senior registrars in community placements only, as case-loads for those in inpatient, liaison and day hospital placements were much lower. The recommended point case-load for senior registrars is $20-30 .^{1}$

The same number of senior registrar placements continued to offer on-call duty in 2008 as in $2007(n=17)$. The on-call requirements of these posts remained the same for both years, with senior registrars first on call in all cases (seven registrars also simultaneously provided second oncall at a different site), the on-call being primarily off site, and frequency of call varying significantly between sites (weekly $16 \%$, fortnightly $26 \%$ and monthly $58 \%$ ).

Administration duties continued to take up a significant amount of senior registrars' time: $52 \%$ reported doing their own filing in 2008 (compared with $32 \%$ in 2007) and $26 \%$ were sending out their own appointments (compared with $64 \%$ in 2007$)$.

\section{Training and education}

No senior registrar reported any difficulty obtaining leave to attend the academic programme in 2008, compared with one in 2007 (4\%), but three registrars reported problems obtaining conference leave in 2008 (11\%), compared with two in 2007 (8\%). Only one person reported difficulty obtaining protected research time of two sessions per week

Table 3 Educational supervision

\begin{tabular}{lcc} 
Guideline & $\begin{array}{c}\text { First audit } \\
\text { cycle, 2007 } \\
\%\end{array}$ & $\begin{array}{c}\text { Second audit } \\
\text { cycle, 2008 } \\
\%\end{array}$ \\
\hline Weekly supervision & 72 & 63 \\
\hline Designated time and day & 84 & 82 \\
\hline Individual supervision session & 100 & 96
\end{tabular}

both years. Table 3 outlines the results obtained for educational supervision.

There was no change in the proportion of senior registrars who had received a written post description from their educational supervisor (19\%). Of concern, the proportion of senior registrars who had completed their annual training plan with their educational supervisor was reduced from $52 \%$ in 2007 to $44 \%$ in 2008 .

\section{Discussion}

Overall, higher training posts compare favourably with standards for training and education, but poorly for working environment, workload and especially safety. Between 2007 and 2008, there were several areas of improvement for senior registrars, notably office space, IT access and time spent sending appointments. Issues related to on-call duty and attendance at lectures and conferences remained broadly the same. Of concern was the increase in caseloads reported by some senior registrars, along with less supervision and fewer annual training plans completed. Most concerning remains the issue of safety, given the very low numbers of senior registrars with personal or officebased alarms, and this requires attention as a matter of urgency.

Previous studies have shown that supervision occurs at recommended levels in about $80 \%$ of higher training placements in child and adolescent psychiatry in the UK. ${ }^{3}$ Worryingly, this audit showed a smaller number of trainees in Ireland receiving appropriate supervision. Indeed, a reduction in this number was noticed in the second audit cycle from 72 to $63 \%$; a more detailed assessment of the supervision process is necessary. Previous research suggested that both trainees and supervisors have a joint responsibility in ensuring that regular supervision takes place. ${ }^{4}$ Guidelines on the structure and content of supervision have been suggested previously. ${ }^{7}$ In a similar vein, annual training plan completion was particularly low, with a reduced number completed from 2007 to 2008 (52\% and $44 \%$ respectively). Once again, responsibility for completion of these plans should fall jointly to senior registrars and their educational supervisors.

In both cycles, very few senior registrars reported any difficulty obtaining leave for academic teaching, conferences or research days. Although outwardly this appears very satisfactory, the usage of the research day requires further study. A study previously carried out showed that $31 \%$ of higher trainees in child and adolescent psychiatry in the UK had no formal training in research methods and a significant number of trainees were undertaking research without resultant publications. ${ }^{8}$ It follows, therefore, that access to appropriate research supervision and training in statistical methods needs assessment to ensure that the maximum benefit of this valuable time is obtained. Making the most economic use of senior registrars' time is also highlighted by the high numbers of senior registrars who report completing administrative duties such as filing, sending out appointments and occasionally typing.

In both cycles, $28 \%$ of placements did not offer any oncall experience. Furthermore, the frequency of on-call duty was such that only $30 \%$ of all senior registrar posts offered 
on-call which met recommendations that all senior registrars should complete 70 sessions over their 3 years' training. Although senior registrars rotated through different posts and would therefore gain some on-call experience, this limited the valuable experience of the acute setting.

Compared with previous studies from the UK, ${ }^{5,9}$ this audit showed a higher rate of access to computers, with all senior registrars in 2008 having some access to a PC.

Aside from in-patient and day hospital posts, point case-loads tended to exceed the CAPSAC-recommended level of 20-30 cases. This number was suggested to allow trainees sufficient time to learn from the cases seen and to research latest evidence-based practice or pertinent literature as appropriate. The number of senior registrars in community posts exceeding this level improved from 2007 but, worryingly, the proportion of those reporting case-loads of more than 50 increased from 28 to $35 \%$. It is unclear why there was such an increase, and this clearly requires attention to assess whether such posts should retain their training status, as outwardly it would appear that service needs took precedence. Further analysis is warranted to examine case-mix, as previous audits in the UK have shown that high-point case-loads often reflect a higher number of cases of self-harm or attention-deficit hyperactivity disorder, which may be lower-intensity work or indeed one-off assessments. ${ }^{6}$

\section{Future direction}

Responsibility for training and accreditation in Ireland is moving to the new College of Psychiatry of Ireland, and it is hoped that this audit will highlight the need for consideration of posts maintaining their training status in light of the limited scale of improvements between the two cycles. At present, child and adolescent mental health services in Ireland are not managed by one organisation and all posts are part of a national rotation. Despite submission of the first audit cycle to training programme directors, there was little improvement, probably reflecting the limited impact at a management level this group currently have. Similarly, the first audit report was submitted just before the typical senior registrar changeover time, thereby limiting the number of changes that could be implemented. It is hoped that enforcement of standards in training posts from the College of Psychiatry of Ireland will facilitate such change.

\section{Acknowledgements}

I thank Dr Louise Gallagher for assistance in design of the audit and Dr David McNamara for reviewing the manuscript.

\section{About the author}

Dermot P. Cohen is Senior Registrar in Child and Adolescent Psychiatry, St John of God Hospital, Stillorgan, Co. Dublin, Ireland.

\section{References}

1 Royal College of Psychiatrists Higher Specialist Training Committee. Child and Adolescent Psychiatry Specialist Advisory Committee Advisory Papers. Royal College of Psychiatrists, 1999.

2 Irish Psychiatric Training Committee. The National Higher Training Scheme in Psychiatry: Training Handbook College of Psychiatry of Ireland, 2008

3 Kingsbury S, Allsopp M. Direct consultant supervision of higher trainees in child and adolescent psychiatry: a survey of expectations and practice. Psychiatr Bull 1994; 18: 225-9.

$4 \mathrm{Ho} \mathrm{H}$, McConville P. Who's happy with supervision? Psychiatr Bull 2004 28: 87-90.

5 Brady J, Knox S. Computer access, skills and training among consultants and psychiatric trainees in Northern Ireland. Psychiatr Bull 2004; 28: 415-7.

6 Sharp N, Morris T. Audit of case-load and case mix of higher specialist trainees in child and adolescent psychiatry. Psychiatr Bull 2002; 26: 212-

7 Cottrell D. Supervision. Adv Psychiatr Treat 1999; 5: 83-8.

8 Smart S, Cottrell D. A survey of training experiences and attitudes of higher specialist trainees in child and adolescent psychiatry. Psychiatr Bull 2000; 24: 302-4.

9 Kotak A, Butler R. Do trainees have adequate access to computers and computer software? Psychiatr Bull 2001; 25: 31-2. 